\title{
Solvent-Enabled Nonenyzmatic Sugar Production from Biomass for Chemical and Biological Upgrading
}

\author{
Jeremy S. Luterbacher, David Martin Alonso, Jacqueline M. Rand, Ydna M. Questell-Santiago, \\ Jher Hau Yeap, Brian F. Pfleger, and James A. Dumesic ${ }^{*[a]}$
}

\begin{abstract}
We recently reported a nonenzymatic biomass deconstruction process for producing carbohydrates using homogeneous mixtures of $\gamma$-valerolactone (GVL) and water as a solvent. A key step in this process is the separation of the GVL from the aqueous phase, enabling GVL recycling and the production of a concentrated aqueous carbohydrate solution. In this study, we demonstrate that phenolic solvents-sec-butylphenol, nonylphenol, and lignin-derived propyl guaiacol-are effective at separating GVL from the aqueous phase using only small amounts of solvent $(0.5 \mathrm{~g}$ per $\mathrm{g}$ of the original water, $\mathrm{GVL}$, and sugar hydrolysate). Furthermore, using nonylphenol, we produced a hydrolysate that supported robust growth and high yields of ethanol ( $0.49 \mathrm{~g} \mathrm{EtOH}$ per g glucose) at an industrially relevant concentration $\left(50.8 \mathrm{~g} \mathrm{~L}^{-1} \mathrm{EtOH}\right)$. These results suggest that using phenolic solvents could be an interesting solution for separating and/or detoxifying aqueous carbohydrate solutions produced using GVL-based biomass deconstruction processes.
\end{abstract}

Lignocellulosic biomass is emerging as a potential renewable feedstock to replace crude oil as a source of fuels and commodity chemicals. For this reason, targeted upgrading routes are being sought to convert biomass to these valuable products. In this context, soluble carbohydrates are an attractive intermediate for biomass upgrading. By weight, structural polysaccharides typically represent between 60 and $80 \mathrm{wt} \%$ of lignocellulosic biomass. In addition, many chemical ${ }^{[1-4]}$ and biological ${ }^{[5-8]}$ processes exist for upgrading carbohydrates to fuels and chemicals.

Different strategies exist for deconstructing biomass hemicellulose (a polymer of $C_{5}$ sugars; mostly xylose) and cellulose (a polymer of cellobiose, a dimer of glucose) to their soluble counterparts. Concentrated mineral acids such as sulfuric or hydrochloric acid have been used to hydrolyze hemicellulose and cellulose to soluble oligomers almost quantitatively. ${ }^{[9-13]}$ Recently, a two-stage process consisting of a thermochemical

[a] Prof. Dr. J. S. Luterbacher, Dr. D. M. Alonso, J. M. Rand,

Y. M. Questell-Santiago, J. H. Yeap, Prof. Dr. B. F. Pfleger,

Prof. Dr. J. A. Dumesic

Department of Chemical and Biological Engineering

University of Wisconsin-Madison

Madison, WI 53706 (USA)

E-mail:dumesic@engr.wisc.edu

Supporting Information for this article is available on the WWW under http://dx.doi.org/10.1002/cssc.201403418. or pretreatment stage followed by enzymatic hydrolysis has been one of the most prominently researched biomass depolymerization methods. ${ }^{[14-17]}$ Both of these methods can achieve soluble carbohydrate yields upwards of $90 \%$ and produce concentrated solutions of carbohydrates $\left(>100 \mathrm{~g} \mathrm{~L}^{-1}\right) \cdot{ }^{[10,13,18]}$ Ionic liquids are also attractive solvents for cellulose dissolution and soluble carbohydrate production. ${ }^{[19,20]}$ Although these processes can be used to produce sugars from biomass, the cost of producing and/or recovering the enzyme, mineral acid, or solvent still represents a significant portion of the final process. ${ }^{[21-23]}$ For this reason, alternate systems using significantly less catalyst have also been explored, including dilute acid hydrolysis $^{[24,25]}$ or hydrothermal biomass depolymerization. ${ }^{[13,26-28]}$ However, at most temperatures (below 510-570 K) and low acid contents $(>3 \%)$, the rate of sugar degradation and dehydration to furans or other degradation products is of the same order of magnitude as the rate of polysaccharide depolymerization, especially for the cellulose fraction of biomass. ${ }^{[13,25,29,30]}$ Therefore, both pure water and dilute acid systems require impractical high-temperature and short-residence time processes to achieve high yields (e.g., $510-670 \mathrm{~K}$ for minutes to seconds). ${ }^{[24,27,29]}$

Organic solvents such as alcohols and ketones have been used during pretreatment to improve the deconstruction of biomass notably by increasing lignin solubility. ${ }^{[31,32]}$ However, these processes still require a subsequent enzymatic hydrolysis step to produce high yields of soluble sugars. Recently, we reported an alternative nonenzymatic process for depolymerizing biomass using $\gamma$-valerolactone (GVL) as a solvent. ${ }^{[33]}$ In this process, a mixture containing $80 \mathrm{wt} \%$ or more GVL, water and $2 \%$ or less $\mathrm{H}_{2} \mathrm{SO}_{4}$ was used to recover $70-90 \%$ of biomass polysaccharides as soluble sugars and $85-95 \%$ of identifiable products once dehydration products (furfural, 5-(hydroxymethyl)furfural, and levulinic acid) were included. The production of carbohydrates in the presence of GVL is improved compared to conversion in pure water due to favorable solvent effects on the acid-catalyzed hydrolysis and dehydration kinetics involved in carbohydrate systems. ${ }^{[34,35]}$ Initial economic modeling of this process revealed that a key design variable for making the process economically feasible is the successful separation and recycling of the GVL solvent. ${ }^{[33]}$ A successful separation was achieved by addition of liquid $\mathrm{CO}_{2}$, which forms a $\mathrm{CO}_{2}$-expanded $\mathrm{GVL}$ phase that, unlike pure $\mathrm{GVL}$, is no longer soluble with water. This addition of $\mathrm{CO}_{2}$ concentrates the sugars 4-5 fold in the aqueous phase using a low-energy GVL separation and reuse process. However, the high pressures ( $>$ $5 \mathrm{MPa}$ ) involved in the $\mathrm{CO}_{2}$ separation process can lead to 
safety issues and increased equipment and energy costs, which led us to explore alternative separation solutions.

Here, we demonstrate that phenolic solvents such as sec-butylphenol (SBP), nonylphenol (NP), or propyl guaiacol (PG, a potential derivative of lignin) ${ }^{[36,37]}$ can be effective phase modifiers to render the GVL phase insoluble with water while avoiding the pressures associated with liquid $\mathrm{CO}_{2}$. These solvents lead to improved separation efficiencies, higher sugar concentrations, and, in the case of separation with nonylphenol, a hydrolysate with reduced toxicity for fermentative organisms even compared with the hydrolysate produced using $\mathrm{CO}_{2}$.

To further explore the separation between GVL and aqueous sugar solutions that we produced from biomass, different organic solvents were screened for their abilities to form a GVLorganic phase insoluble in the aqueous solution. Several solvents including alkylphenols such as NP, SBP, or tert-butylphenol (TBP) formed such a phase. We also tested PG, a potential product of lignin hydrogenolysis, ${ }^{[36,37]}$ which successfully formed similar phases. We then explored the effect of increasing the solvent content on the effective recovery of sugars (monomers and oligomers) produced from corn stover in the aqueous phase and on the removal of GVL from said aqueous phase (Figure 1). We performed similar experiments using $\mathrm{CO}_{2}$ for comparison purposes. Carbohydrate recovery of both $C_{5}$ and $C_{6}$ sugars (monomers and oligomers) is maximized when an amount of NP (Figure 1A), PG (Figure 1B), or SBP (Figure $1 \mathrm{C}$ ) corresponding to $50 \%$ of the original water, $\mathrm{GVL}$, and sugar solution is added. This maximum is the result of two competing effects: (1) the increasing amount of organic phase, which increases the total quantity of sugars extracted in that phase; and (2) the increasing partition of the sugars to the aqueous phase as more solvent is added (Table S1 in the Supporting Information), which decreases the concentration of sugars in the organic phase. The increasing partition of $C_{5}$ and $\mathrm{C}_{6}$ sugars into the aqueous phase occurs as the organic phase transitions from containing mostly GVL to containing mostly the added organic solvent. The increase in sugar partition to the aqueous phase is likely due to the fact that sugars are somewhat soluble in GVL but almost completely insoluble in the phenolic solvents we are using. In contrast to these maxima in sugar recovery, we see that sugar recovery remains relatively constant as more solvent is added when TBP (Figure 1D) or $\mathrm{CO}_{2}$ (Figure $1 \mathrm{~F}$ ) are used as solvents. The aforementioned variations in partition coefficients are less pronounced for GVL itself (Table S1), and therefore, a much more monotonic decrease in GVL concentration is observed with increased addition of external solvent (Figure 1).

To increase the total extracted GVL and further reduce its concentration in the aqueous phase, we studied subsequent extractions using each of these organic solvents. In these studies, a first extraction using an amount of external solvent corresponding to $50 \%$ of the weight of the extracted solution was used in combination with a second, third, and fourth subsequent extraction using an amount of external solvent corresponding to $25 \%$ of the weight of the extracted solution (Figure $2 \mathrm{~A}-\mathrm{C}$ ). We did not test subsequent extractions using TBP because its ability to extract GVL from the aqueous phase was limited compared to the other solvents (Figure 1D and Table S1). The efficiency of GVL removal increased according to the GVL partition coefficient observed during the first extractions (Figure 2). Therefore, after four extractions, the GVL content in the aqueous phase was the lowest (under $0.5 \mathrm{wt} \%$ ) when SBP was used as the extraction solvent, which showed partition coefficients as high as 6.4 (Table S1, Figure 2C). The aqueous phases extracted with NP and PG contained 1.7 and $1.6 \mathrm{wt} \% \mathrm{GVL}$, respectively, after four subsequent extractions. This observation reflects the fact that these two solvents had lower GVL partition coefficients than SBP. The final GVL concentration in the aqueous phase was $0.5 \mathrm{wt} \%$ after four subsequent extractions using $\mathrm{CO}_{2}$ (Figure 2D). Given the greater amount of $\mathrm{CO}_{2}$ used compared to the other organic solvents, this behavior indicates that $\mathrm{CO}_{2}$ shows reduced extraction efficiency compared to the other organic solvents.

The removal of a significant portion of the GVL after the first extraction led to a 5-6-fold increase in the sugar concentration in the resulting aqueous phase compared to the initial mixture (Figure 2E). After this first extraction, oligomers were hydrolyzed to form more easily metabolized monomers by adding $0.025 \mathrm{molL}^{-1} \mathrm{H}_{2} \mathrm{SO}_{4}$ to the aqueous phase. $\mathrm{H}_{2} \mathrm{SO}_{4}$ was used to compensate for the neutralization of the initial acid by the biomass. The entire solution was heated to $410 \mathrm{~K}$ for $100 \mathrm{~min}$. Typical monomer yields were $90 \pm 5 \%$. This range of results is typical for oligomer hydrolysis and is due to various sources of uncertainty including the capacity of biomass to neutralize acidity capacity, the fraction of oligomers, and the partitioning of oligomers versus monomers during the initial extraction. After the four extractions, the total concentration of sugars $\left(C_{5}+C_{6}\right.$ sugars) further increased to $9.9,11.4,10.6$, and $7.8 \mathrm{wt} \%$ for $\mathrm{NP}, \mathrm{PG}, \mathrm{SBP}$, and $\mathrm{CO}_{2}$ respectively (Figure $2 \mathrm{E}$ ). Despite this difference in sugar concentrations, sugar recovery in the aqueous phase was remarkably high (>96\%) for all solvents following the initial extraction. In addition to these results, we tested the extraction procedure using NP and $\mathrm{CO}_{2}$ on a more concentrated biomass feed that we are able to produce using a twostep nonenzymatic hydrolysis process. ${ }^{[33]}$ We observed higher separation efficiencies (by 7-10\%) due to the solubility of sugar in the organic phase remaining constant despite an increase in the total amount of sugars. This resulted in increased final carbohydrate concentrations of 15.3 and $12.7 \mathrm{wt} \%$ for NP and $\mathrm{CO}_{2}$ extraction, respectively.

All resulting monomer solutions discussed above were tested for their potential in biological upgrading by diluting them with minimal media and inoculating them with S. cervisiae PE2, which is a glucose-fermenting industrial strain (Table 1). Initial aeration of the yeast strain was accomplished by a single injection of air. ${ }^{[33]}$ SBP- and PG-extracted solutions only supported growth after considerable dilutions (Table 1). Although we were not able to detect any of the two solvents in the hydrolysate using GC, trace amounts were likely present and led to toxicity for microorganisms. As we previously reported, the $\mathrm{CO}_{2}$-extracted aqueous sugar solution was able to support robust microbial growth once it was diluted to $75 \%$ of its original solution, producing glucose-to-ethanol yields corresponding to $87 \%$ of theoretical yield. ${ }^{[33]}$ In this study, by using 

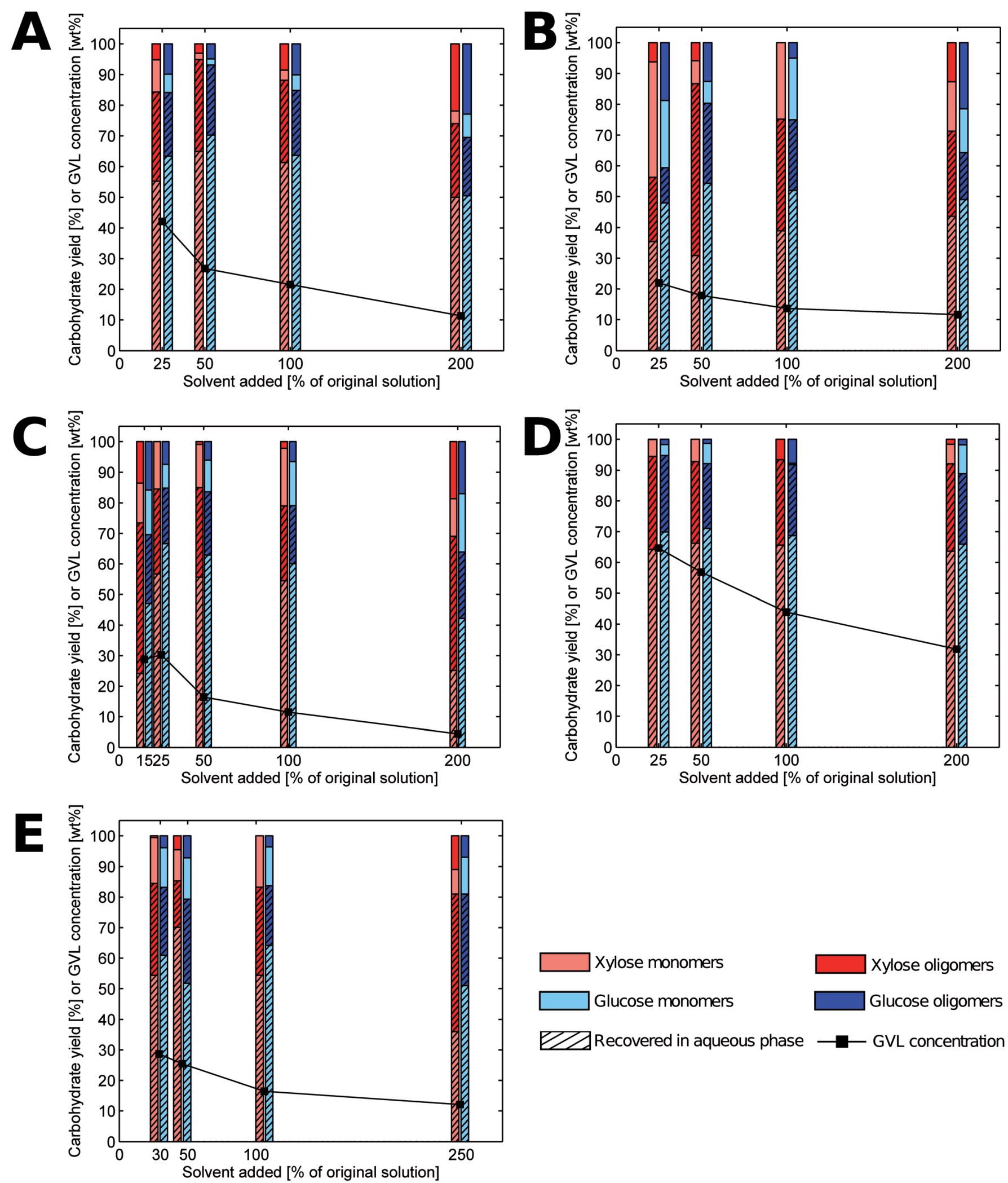

Figure 1. Effect of added solvent on carbohydrate recovery in the aqueous phase from $80 \% \mathrm{GVL} / 20 \%$ water corn stover-derived hydrolysates for (A) NP, (B) PG, (C) SBP, (D) TBP, and (E) $\mathrm{CO}_{2}$. The original solution refers to the original water, $\mathrm{GVL}$, and sugar hydrolysate.

larger vials and fermentation volumes, we were able to better control the initial amount of oxygen that was injected into the reactor, increasing our glucose-to-ethanol yields to $96 \%$ of the- oretical yield (Figure S1 and Table 1). Our final ethanol concentration reached $34.7 \mathrm{~g}$ per $\mathrm{kg}$ glucose. Although we did not use an organism that metabolizes xylose, conversion of xylose 
A

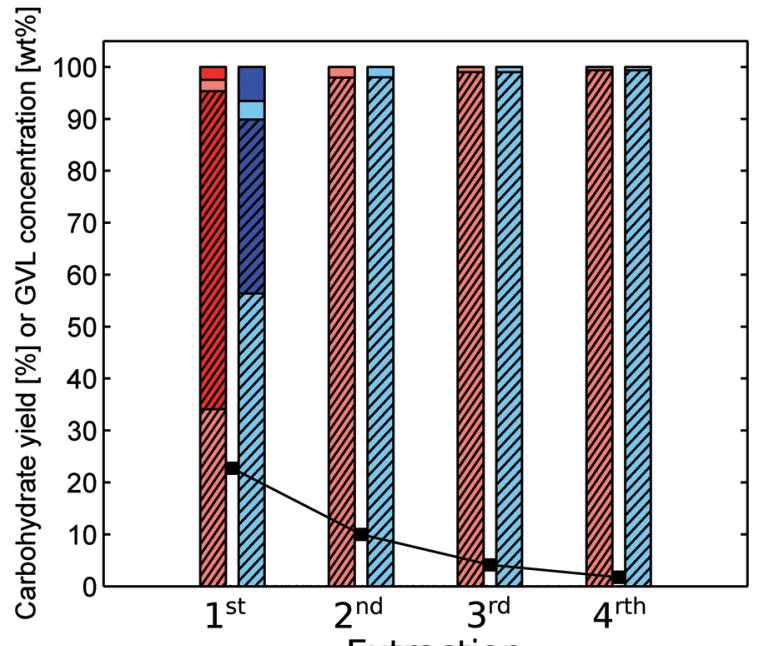

C

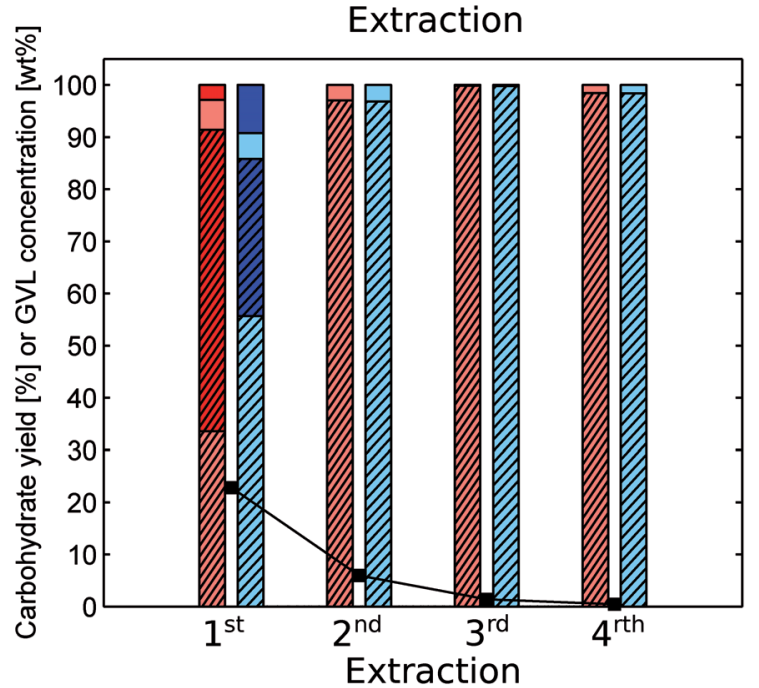

B

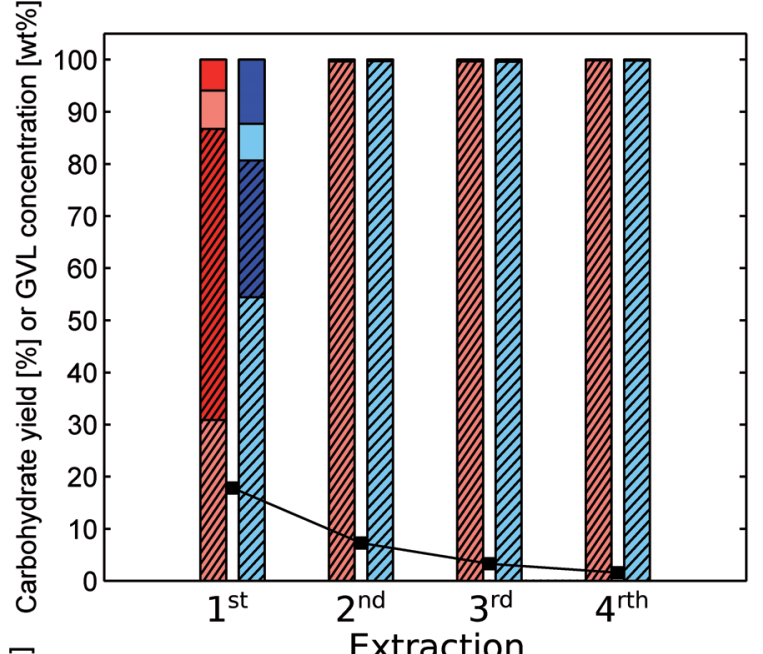

D

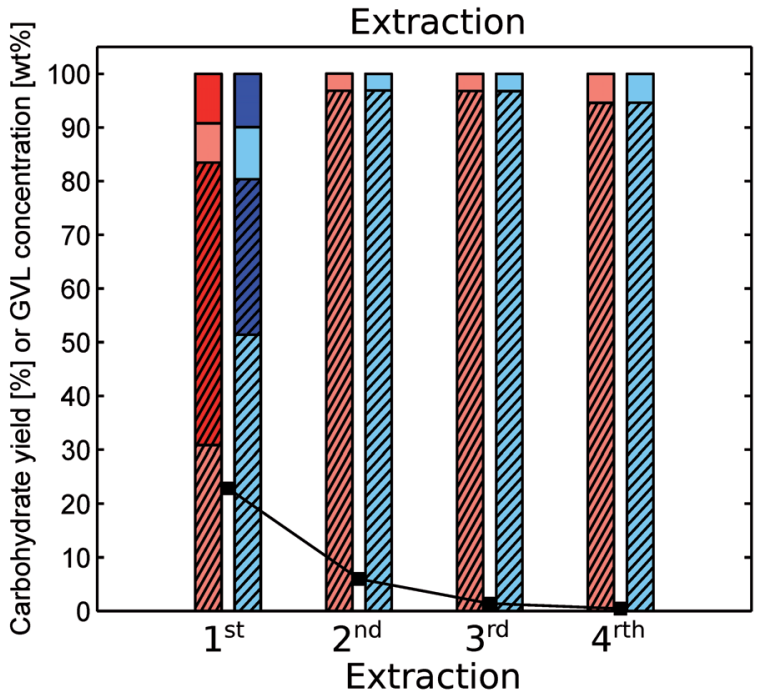

E

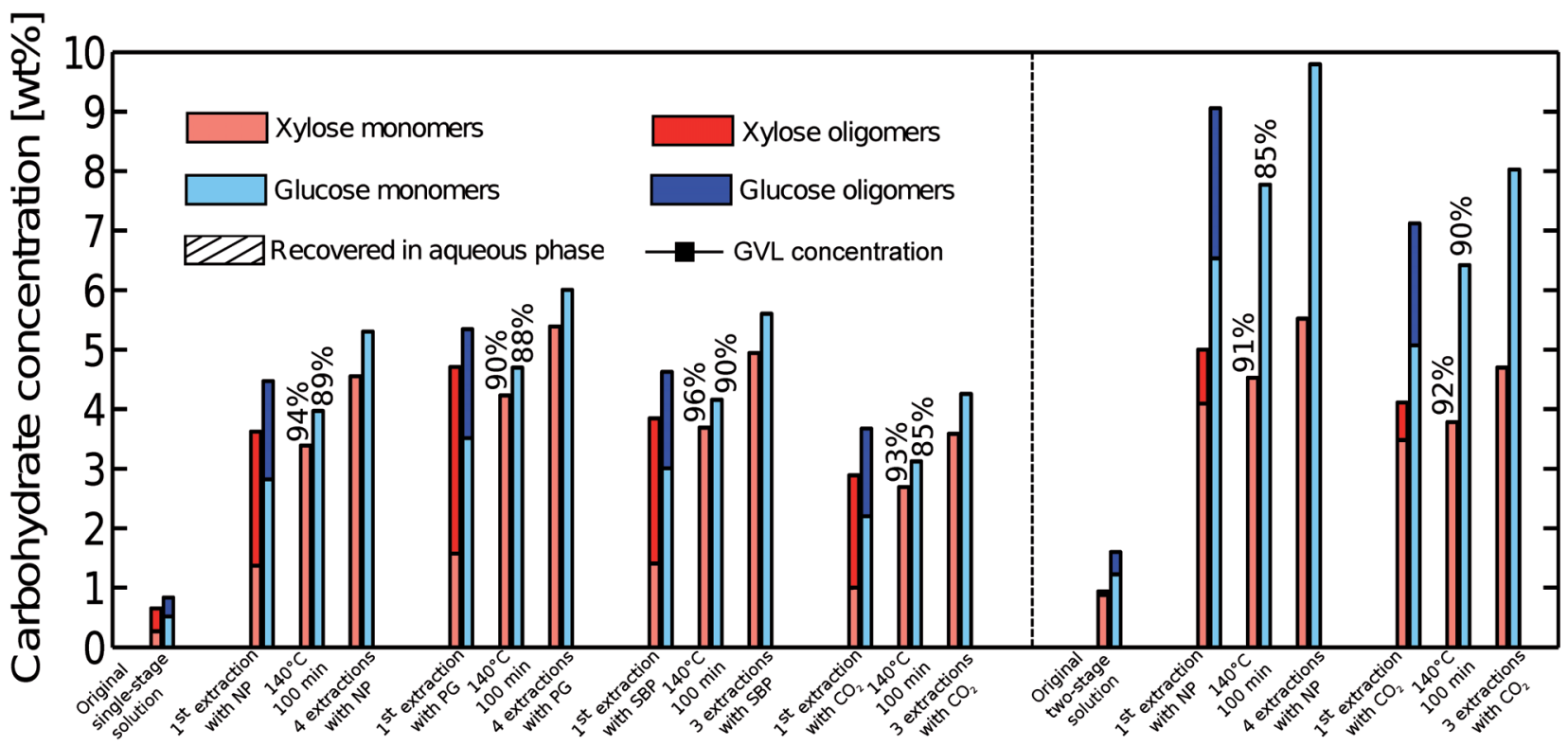

Figure 2. Subsequent extractions of $80 \% \mathrm{GVL} / 20 \%$ water corn stover-derived hydrolysates for (A) NP, (B) PG, (C) SBP, and (D) CO 2 . (E) Evolution of concentration with subsequent extractions with " $140{ }^{\circ} \mathrm{C}, 100 \mathrm{~min}$ " designating the step of hydrolyzing oligomers to monomers after the first extraction. Extraction results from hydrolysates produced using the single-stage depolymerization process are shown to the left of the dashed line, whereas results from hydrolysates produced using the two-stage depolymerization process are shown to the right of the dashed line. The data presented on (E) is also given in Table S2 (Supporting Information). 


\begin{tabular}{|c|c|c|c|c|c|}
\hline $\begin{array}{l}\text { Separation } \\
\text { solvent }\end{array}$ & $\begin{array}{l}\text { Minimal dilution } \\
\text { for growth [\%] }\end{array}$ & $\begin{array}{l}\text { Initial glucose } \\
\text { concentration }{ }^{[a]}\left[\mathrm{g} \mathrm{L}^{-1}\right]\end{array}$ & $\begin{array}{l}\text { Growth } \\
\text { time }[\mathrm{h}]\end{array}$ & $\begin{array}{l}\text { Final ethanol } \\
\text { concentration }\left[\mathrm{g} \mathrm{L}^{-1}\right]\end{array}$ & $\begin{array}{l}\text { Yield } \\
\text { [\% of theoretical] }\end{array}$ \\
\hline \multirow[t]{2}{*}{$\mathrm{CO}_{2}$} & 75 & 42.8 & 96.0 & 18.9 & 86 \\
\hline & $75^{[b]}$ & $71.0^{[\mathrm{bb}]}$ & $72.0^{[b]}$ & $34.7^{[b]}$ & $96^{[b]}$ \\
\hline \multirow[t]{2}{*}{ NP } & 90 & 51.6 & 168.0 & 18.8 & 72 \\
\hline & 90 & 102.5 & 100.0 & 50.8 & 96 \\
\hline SBP & 17 & 9.5 & 168.0 & 1.3 & 27 \\
\hline PG & 33 & 23.7 & 168.0 & 7.6 & 62 \\
\hline
\end{tabular}

[a] Refers to the glucose concentration in the corn stover-derived hydrolysate after the dilution with minimal media, but before fermentation. [b] Concentration profiles over the course of fermentation for this data are given in Figure $\mathrm{S} 1$.

hydrolysates that are compatible with biological upgrading and require almost no dilution for robust microbial growth to occur. The obtained and potential ethanol concentrations that we reported for the conversion of NP-extracted hydrolyzates (50.8 and $81 \mathrm{~g} \mathrm{~kg}^{-1}$ ) are in the range of the highest ethanol concentrations obtained using enzymatic processes. ${ }^{[4,45]}$ Phenolic solvents can provide a more effective separation, require lower pressure, and can be used to avoid significant mechanical energy for repressuriza-

and other $C_{5}$ sugars is essential as they represent a significant portion of biomass's structural carbohydrates and 35-45 wt \% of the sugars we produce. Nevertheless, efficient co-utilization of xylose and glucose was demonstrated in several studies using other mutant $S$. cerevisiae strains. ${ }^{[5,38,39]}$ If we assume that ethanol can be produced at similar yields to those obtained from glucose, our potential ethanol concentration would be $56 \mathrm{~g} \mathrm{~kg}^{-1}$.

In the case of NP extraction, we observed robust growth using $90 \%$ diluted hydrolysate (Table 1). This dilution was the minimum required dilution for us to add a salts supplement solution to the hydrolysate. Therefore, it is possible that NP-extracted hydrolysate could have supported growth without dilution. We observed this growth after a $90 \%$ dilution when using both the hydrolysate produced by means of the single or the two-stage depolymerization process. Hydrolysate detoxification during fermentation using organic solvents has been previously demonstrated in butanol fermentation where continuous extraction during fermentation was performed to avoid product inhibition. ${ }^{[40]}$ Interestingly, NP was found to be toxic to Clostridium acetobutylicum. However, several yeasts have demonstrated tolerance to NP and even the ability to degrade it. ${ }^{[41]}$

As discussed above, the aqueous carbohydrate solution produced using NP extraction had a higher initial carbohydrate concentration than the $\mathrm{CO}_{2}$ phase. This higher concentration, combined with the lower dilution and a fermentation yield corresponding to $96 \%$ of theoretical yield led to ethanol concentrations reaching $50.8 \mathrm{~g}$ per $\mathrm{kg}$ glucose alone. Again, if one assumes that xylose could be converted to ethanol at similar yields, this could lead to ethanol concentrations close to $81 \mathrm{~g} \mathrm{~kg}^{-1}$. Considering that typical industrial scenarios include target ethanol titers around $50 \mathrm{~g} \mathrm{~kg}^{-1}$ ( $\left.5 \mathrm{wt} \%\right)$ to maintain reasonable separation costs, our potential ethanol concentration is consistent with that required for industrial ethanol production. ${ }^{[42,43]}$

In conclusion, alkylphenols are attractive solvents to separate $\gamma$-valerolactone (GVL) and water after depolymerization of biomass and recover a concentrated aqueous phase of carbohydrates. Nonylphenol is especially well suited to producing tion compared to $\mathrm{CO}_{2}$. However, these solvents must then be separated from GVL by distillation. Although such a step is often energy intensive, past simulation studies using alkylphenol solvents have shown that GVL's low heat of vaporization along with solvent design and high GVL concentrations can make this process energetically feasible. ${ }^{[46]}$ However, careful heat integration and process design will likely be necessary if these solvents are to be used in an industrial extraction process.

\section{Acknowledgements}

This work was supported by the Great Lakes Bioenergy Research Center (http://www.glbrc.org), supported by the U.S. Department of Energy, through Cooperative Agreement DE-FC02-07ER64494 between the Board of Regents of the University of Wisconsin System and the U.S. Department of Energy and the National Science Foundation (CBET-1149678). J.S.L. acknowledges support from the Swiss National Science Foundation. J.M.R. is the recipient of a NSF graduate research fellowship.

Keywords: biomass $\cdot$ biorefinery $\cdot$ catalysis $\cdot$ sugars
valerolactone

[1] R. D. Cortright, R. R. Davda, J. Dumesic, Nature 2002, 418, 964-967.

[2] E. L. Kunkes, D. A. Simonetti, R. M. West, J. C. Serrano-Ruiz, C. A. Gartner, J. A. Dumesic, Science 2008, 322, 417.

[3] Y. Román-Leshkov, C. J. Barrett, Z. Y. Liu, J. A. Dumesic, Nature 2007, 447, $982-985$.

[4] G. W. Huber, J. N. Chheda, C. J. Barrett, J. A. Dumesic, Science 2005, 308, $1446-1450$.

[5] M. W. Lau, B. E. Dale, Proc. Natl. Acad. Sci. USA 2009, 106, 1368-1373.

[6] S. Atsumi, T. Hanai, J. C. Liao, Nature 2008, 451, 86-89.

[7] S. K. Lee, H. Chou, T. S. Ham, T. S. Lee, J. D. Keasling, Curr. Opin. Biotechnol. 2008, 19, 556-563.

[8] J. T. Youngquist, J. P. Rose, B. F. Pfleger, Appl. Microbiol. Biotechnol. 2013, 97, 5149-5159.

[9] A. Sluiter, B. Hames, R. Ruiz, C. Scarlata, J. Sluiter, D. Templeton, D. Crocker, Determination of Structural Carbohydrates and Lignin in Biomass, National Renewable Energy Laboratory, Golden, CO, 2004.

[10] W. L. Faith, Ind. Eng. Chem. 1945, 37, 9-11.

[11] F. Bergius, Ind. Eng. Chem. 1937, 29, 247-253. 
[12] M. Oshima, Wood Chemistry Process Engineering Aspects, Noyes Development, Pearl River, 1965.

[13] J. S. Luterbacher, D. M. Alonso, J. A. Dumesic, Green Chem. 2014, 16 $4816-4838$

[14] C. E. Wyman, B. E. Dale, R. T. Elander, M. Holtzapple, M. R. Ladisch, Y. Y. Lee, C. Mitchinson, J. N. Saddler, Biotechnol. Prog. 2009, 25, 333-339.

[15] C. E. Wyman, B. E. Dale, R. T. Elander, M. Holtzapple, M. R. Ladisch, Y. Y. Lee, Bioresour. Technol. 2005, 96, 2026-2032.

[16] C. R. Wilke, R. D. Yang, Appl. Polym. Symp. 1975, 175-188.

[17] E. T. Reese, Appl. Microbiol. 1956, 4, 39-45.

[18] J. S. Luterbacher, Q. Chew, Y. Li, J. W. Tester, L. P. Walker, Energy Environ. Sci. 2012, 5, 6990-7000.

[19] R. P. Swatloski, S. K. Spear, J. D. Holbrey, R. D. Rogers, J. Am. Chem. Soc. 2002, 124, 4974-4975.

[20] J. B. Binder, R. T. Raines, Proc. Natl. Acad. Sci. USA 2010, 107, 4516-4521.

[21] M. von Sivers, G. Zacchi, Bioresour. Technol. 1995, 51, 43-52.

[22] D. Klein-Marcuschamer, P. Oleskowicz-Popiel, B. A. Simmons, H. W. Blanch, Biotechnol. Bioeng. 2012, 109, 1083-1087.

[23] S. M. Sen, J. B. Binder, R. T. Raines, C. T. Maravelias, Biofuels Bioprod. Biorefining 2012, 6, 444-452.

[24] J. F. Harris, A. J. Baker, A. Conner, T. Jeffries, J. Minor, R. Pettersen, R. Scott, E. Springer, T. Wegner, J. Zerbe, Two-Stage, Dilute Sulfuric Acid Hydrolysis of Wood: An Investigation of Fundamentals (Gen. Tech. Rep. FPL) 1985, p. 45

[25] O. Bobleter, Prog. Polym. Sci. 1994, 19, 797-841.

[26] M. Sasaki, B. Kabyemela, R. Malaluan, S. Hirose, N. Takeda, T. Adschiri, K. Arai, J. Supercrit. Fluids 1998, 13, $261-268$

[27] M. Sasaki, Z. Fang, Y. Fukushima, T. Adschiri, K. Arai, Ind. Eng. Chem. Res. 2000, 39, 2883-2890.

[28] S. Kilambi, K. L. Kadam, Production of Fermentable Sugars and Lignin from Biomass Using Supercritical Fluids, US patent 20130239954, 2013.

[29] A. A. Peterson, F. Vogel, R. P. Lachance, M. Fröling, M. J. Antal, Jr., J. W. Tester, Energy Environ. Sci. 2008, 1, 32-65.

[30] R. D. Fagan, H. E. Grethlein, A. O. Converse, A. Porteous, Environ. Sci. Technol. 1971, 5, 545-547.
[31] P. Sannigrahi, A. J. Ragauskas in Aqueous Pretreatment of Plant Biomass for Biological and Chemical Conversion to Fuels and Chemicals (Ed.: C. E. Wyman), 2013, Wiley, Chichester, pp. $201-222$.

[32] G. T. Tsao, M. R. Ladisch, C. M. Ladisch, T.-A. Hsu, Fractionation Then Hydrolysis of the Remaining Cellulose, US patent 4281063, 1981.

[33] J. S. Luterbacher, J. M. Rand, D. M. Alonso, J. Han, J. T. Youngquist, C. T. Maravelias, B. F. Pfleger, J. A. Dumesic, Science 2014, 343, 277-280.

[34] M. A. Mellmer, D. M. Alonso, J. S. Luterbacher, J. M. R. Gallo, J. A. Dumesic, Green Chem. 2014, 16, 4659-4662.

[35] M. A. Mellmer, C. Sener, J. M. R. Gallo, J. S. Luterbacher, D. M. Alonso, J. A. Dumesic, Angew. Chem. Int. Ed. 2014, 53, 11872-11875; Angew. Chem. 2014, 126, 12066-12069.

[36] P. Azadi, R. Carrasquillo-Flores, Y. J. Pagán-Torres, E. I. Gürbüz, R. Farnood, J. A. Dumesic, Green Chem. 2012, 14, 1573-1576.

[37] N. Yan, C. Zhao, P. J. Dyson, C. Wang, L. Liu, Y. Kou, ChemSusChem 2008, 1, 626-629.

[38] Y.-S. Jin, H. Alper, Y.-T. Yang, G. Stephanopoulos, Appl. Environ. Microbiol. 2005, 71, 8249-8256.

[39] T. W. Jeffries, Curr. Opin. Biotechnol. 2006, 17, 320-326.

[40] S. R. Roffler, P. H. W. Blanch, P. C. R. Wilke, Bioprocess Eng. 1987, 2, 1-12.

[41] P. F. X. Corvini, A. Schäffer, D. Schlosser, Appl. Microbiol. Biotechnol. 2006, 72, 223-243.

[42] F. K. Kazi, J. A. Fortman, R. P. Anex, D. D. Hsu, A. Aden, A. Dutta, G. Kothandaraman, Fuel 2010, 89, S20-S28.

[43] D. Humbird, R. Davis, L. Tao, C. Kinchin, D. Hsu, A. Aden, P. Schoen, J. Lukas, B. Olthof, M. Worley, Process Design and Economics for Biochemical Conversion of Lignocellulosic Biomass to Ethanol, National Renewable Energy Laboratory Report NREL, TP-5100-47764, 2011.

[44] D. Cannella, H. Jørgensen, Biotechnol. Bioeng. 2014, 111, 59-68.

[45] A. A. Modenbach, S. E. Nokes, Biomass Bioenergy 2013, 56, 526-544.

[46] D. M. Alonso, S. G. Wettstein, J. Q. Bond, T. W. Root, J. A. Dumesic, ChemSusChem 2011, 4, 1078-1081.

Received: December 15, 2014

Revised: February 11, 2015

Published online on March 17, 2015 